\title{
Diagnosis of Aortic Coarctation Using Renal Dopplersonography, a Case Report
}

\author{
Ahmad Rezaee1, Leili Ebrahimi2 ${ }^{*}$, Sedigheh Saedi ${ }^{3}$ \\ ${ }^{1}$ Department of Radiology, Hamedan University of Medical Science, Hamedan, Iran \\ ${ }^{2}$ Department of Cardiology, Kerman University of Medical Science, Kerman, Iran \\ ${ }^{3}$ Rajaei Cardiovascular, Medical, Research Center, Iran University of Medical Sciences, Tehran, Iran \\ Email: Ahmad Rezaee20@yahoo.com, lilieage@gmail.com, sedsaedi@gmail.com
}

Received 2 April 2015; accepted 22 May 2015; published 27 May 2015

Copyright (C) 2015 by authors and Scientific Research Publishing Inc.

This work is licensed under the Creative Commons Attribution International License (CC BY).

http://creativecommons.org/licenses/by/4.0/

(c) (i) Open Access

\begin{abstract}
Renal Doppler sonography has proved efficacious in detection of several important underlying causes of secondary hypertension. Its application in diagnosis of congenital arterial abnormalities has also recently received attention. Herein, we presented a patient who was diagnosed with coarctation of the aorta (COA) using renal Doppler sonography during work-up for secondary hypertension.
\end{abstract}

Keywords

COA

\section{Introduction}

Coarctation of the aorta (COA) is a relatively common congenital abnormality and accounts for $5 \%-8 \%$ of congenital heart defects. The diagnosis of COA may be delayed and only detected when serious complications such as congestive heart failure (usually in infants) or hypertension (commonly in older children) appear [1] [2]. Although the diagnosis is mainly based on finding of a discrepancy between arm and leg systemic blood pressures in physical examination or hypertension resistant to medical treatment, this signs are sometimes overlooked. Because of high efficacy of renal Doppler sonography for detection of secondary hypertension [3]-[5], its application for managing arterial abnormalities has recently been paid attention to. Herein, we presented a 27- year-old male with secondary hypertension that was finally diagnosed to be caused by COA using renal Doppler sonography.

*Corresponding author.

How to cite this paper: Rezaee, A., Ebrahimi, L. and Saedi, S. (2015) Diagnosis of Aortic Coarctation Using Renal Dopplersonography, a Case Report. Case Reports in Clinical Medicine, 4, 189-192. http://dx.doi.org/10.4236/crcm.2015.45038 


\section{Case Report}

A 27-year-old male was referred to our facility for working up of secondary causes of resistant hypertension. The patient had no family history or known risk factors for hypertension. General physical examination was unremarkable except for a blood pressure (BP) of 190/110 in both arms. No cardiac murmurs or bruit was detected. Lab data and blood biochemistry revealed no specific abnormality. Renal Doppler sonography was performed to screen for potential causes of secondary hypertension i.e. renal artery stenosis. During the study, Tardusparvus pulse waves were noted in both intra-renal arteries (Figure 1(a) and Figure 1(b)). A subsequent renal arteries CT angiography did not show evidence of renal artery stenosis and both adrenal glands appeared normal but a tortuous and engorged mammillary arteries was noted along the abdominal wall (Figure 2). The patient underwent CT angiography of aorta that revealed a stenotic lesion in the isthmus of the aorta compatible with severe coarctation (Figure 3 and Figure 4) and he was counseled and referred for corrective surgery.

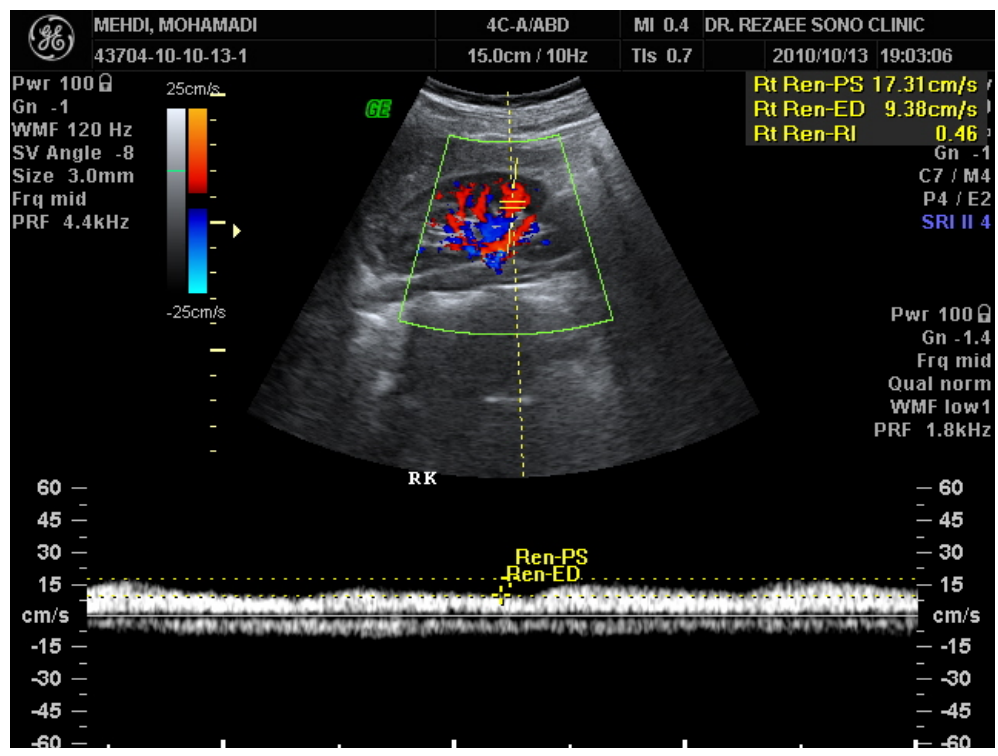

(a)

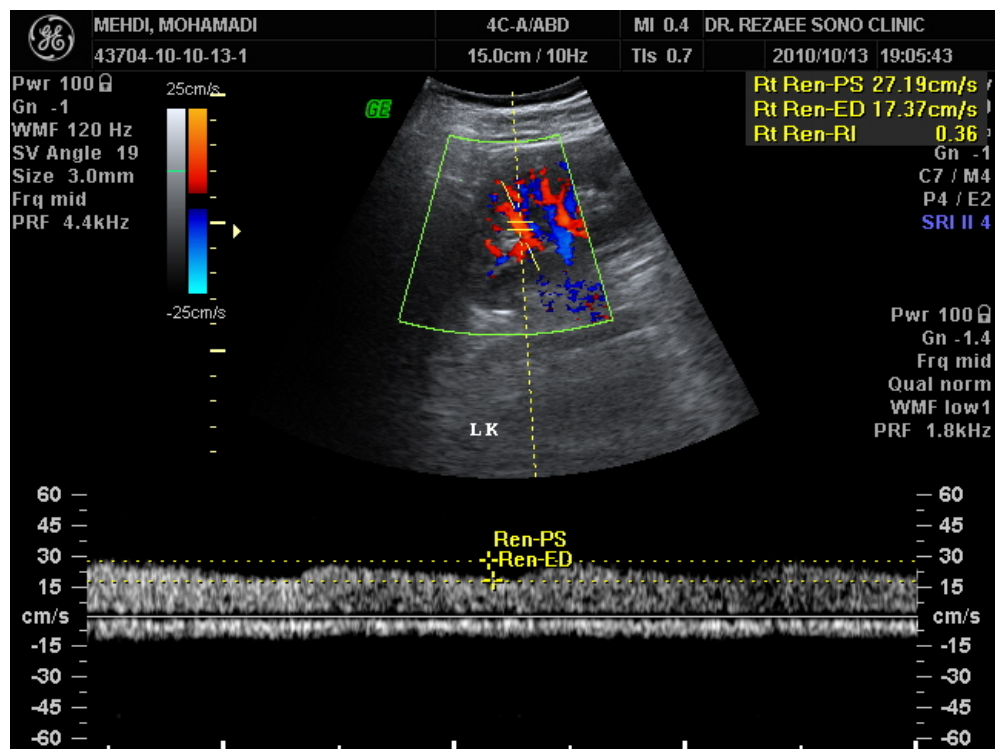

(b)

Figure 1. Doppler study of intra-renal arteries shows tardusparvus wave in both side. 


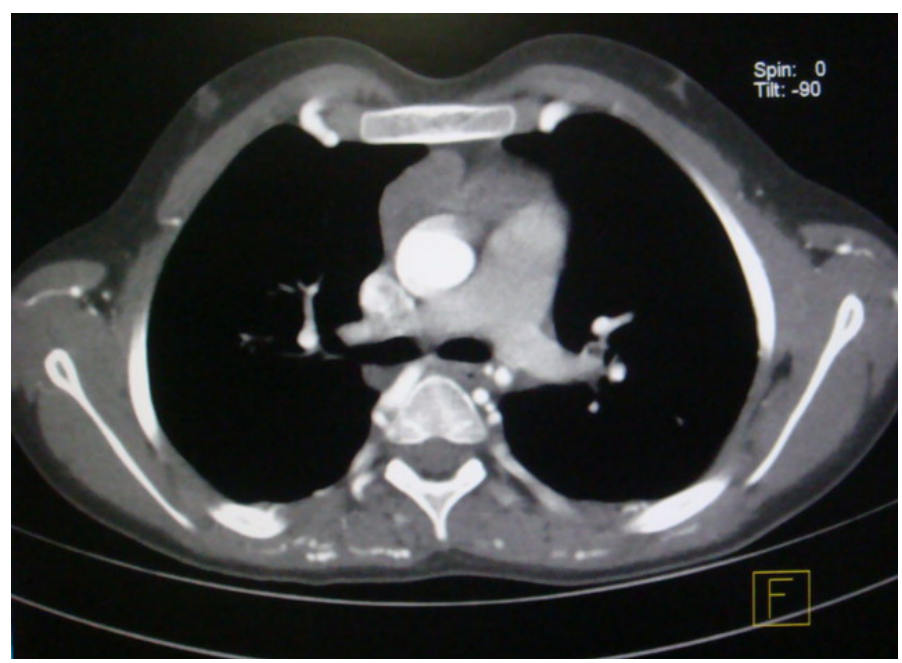

Figure 2. Axial CT scan depicting tortuous and engorged chest wall areteris due to collateral formation.

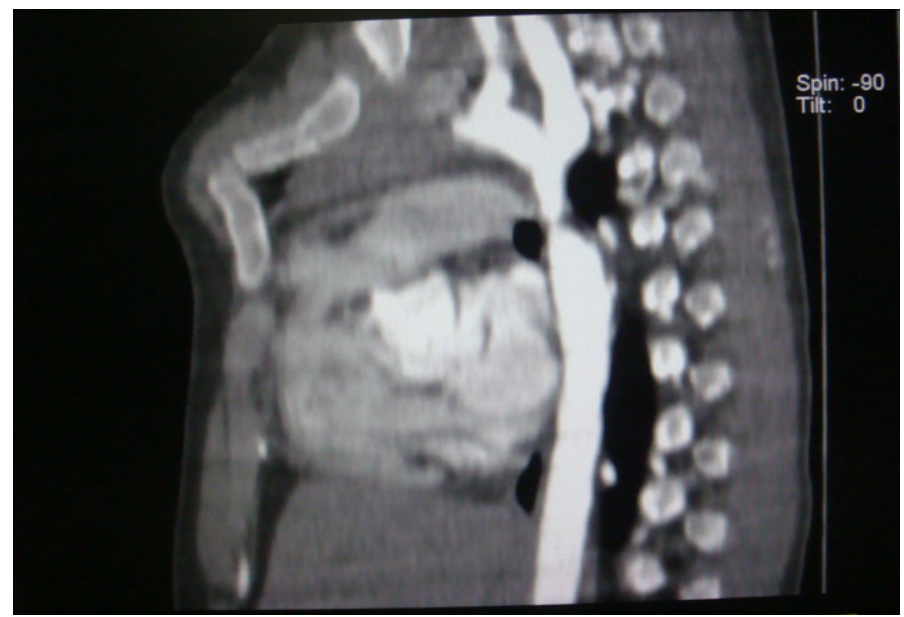

Figure 3. Sagittalreformated CT angiography shows severe coarctation in descending aorta.

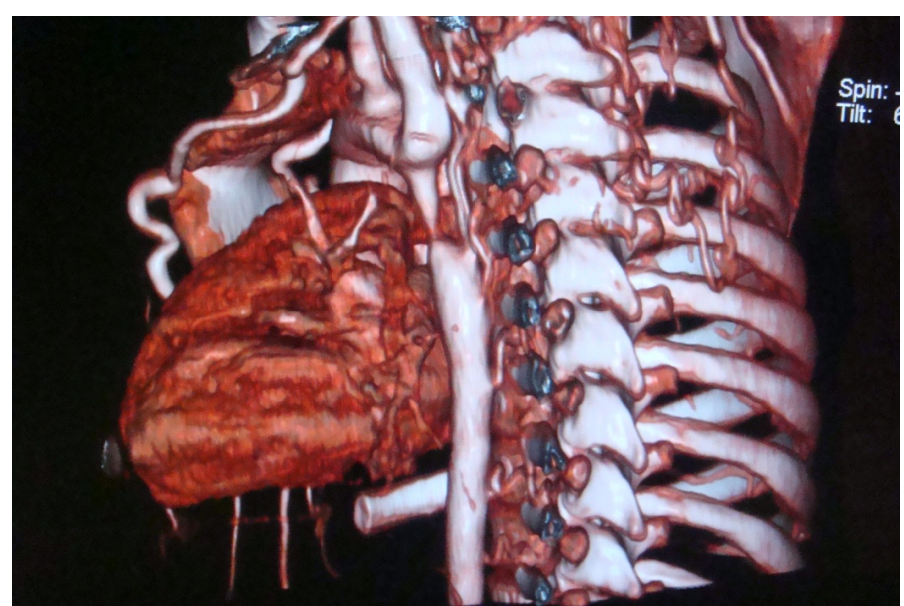

Figure 4. 3D reconstruction shows severe coarctation in descending aorta, note engorged inernalmamillary arteries. 


\section{Discussion}

Many experts believe that the suspicion of stenosis in aorta raised during doppler sonography is a more reliable sign for possible coarcatation of aorta than basic physical examination.

Considerable differences in the flow signals recorded in the descending aorta of those affected with COA are a major hallmark that does not exist in normal subjects. Color Doppler sonography demonstrates high-velocity flow in the descending aorta in most instances. However, Doppler based estimation of gradients does not always fully correlate with angiographically measured gradients [6]-[8]. It should also be kept in mind that in some patients, normal flow velocities are recorded in spite of existence of clinical signs of COA and in fact the finding of normal flow velocities does not exclude the presence of an obstructive lesion [9].

\section{Conclusions}

The main differential diagnosis for COA Doppler finding is bilateral renal arteries stenosis. The main color Doppler findings favor for COA are tardusparvus waves in bilateral renal segmental arteries and saw-teeth pattern waves in abdominal aorta, especially when upper limbs arterial waves have normal pattern.

Renal Doppler ultrasonography could be recommended as a noninvasive, affordable and cost effective screening tool in detection of congenital arterial abnormalities or as part of general work-up for secondary causes of hypertension before proceeding with more elaborate and costly methods like CT-angiography.

\section{References}

[1] Therrien, J. and Webb, G.D. (2005) Congenital Heart Disease in Children and Adults. In: Zipes, D.P., Libby, P., Bonow, R. and Braunwald, E., Eds., Braunwald's Heart Disease: A Textbook of Cardiovascular Medicine, 7th Edition, W.B. Saunders, Philadelphia, 1992-2011.

[2] Daghero, F., Bueno, N., Peirone, A., Ochoa, J., Torres, G.F. and Ganame, J. (2008) Coarctation of the Abdominal Aorta, An Uncommon Cause of Arterial Hypertension and Stroke. Circulation: Cardiovascular Imaging, 1, e4-e6. http://dx.doi.org/10.1161/CIRCIMAGING.108.767947

[3] Jung, Y.-H., Kim, K.-W., Kim, D.-Y. and Lee, C.-S. (2011) A Case of Coarctation of the Aorta Diagnosed by TardusParvus Renal Doppler Flow Patterns. The Korean Journal of Internal Medicine, 26, 216-217. http://dx.doi.org/10.3904/kjim.2011.26.2.216

[4] Abuagla, E.M. and Pei, T.S. (2014) Utility of Color Doppler Ultrasound in the Evaluation of Renal Artery Stenosis in Comparison with Contrast-Enhanced Magnetic Resonance Angiography. Saudi Journal of Kidney Diseases and Transplantation, 25, 309-315.

[5] Tafur-Soto, J.D. and White, C.J. (2015) Renal Artery Stenosis. Cardiology Clinics, 33, 59-73. http://dx.doi.org/10.1016/j.ccl.2014.09.006

[6] Rao, P.S. and Carey, P. (1989) Doppler Ultrasound in the Prediction of Pressure Gradients across Aortic Coarctation. American Heart Journal, 118, 299-307. http://dx.doi.org/10.1016/0002-8703(89)90189-0

[7] Voiculescu, A., Heusch, A., Düppers, P., Pourhassan, S., Klee, D., Rump, L.C. and Sandmann, W. (2014) Duplex Ultrasound Findings before and after Surgery in Children and Adolescents with Renovascular Hypertension. Ultrasound in Medicine and Biology, 40, 2786-2793. http://dx.doi.org/10.1016/j.ultrasmedbio.2014.07.011

[8] Atalabi, O. and Lee, E.Y. (2008) Bilateral Tardus-Parvus Waveform in Kidneys Secondary to Mid-Aortic Syndrome in a Hypertensive Child. Pediatric Radiology, 38, 816. http://dx.doi.org/10.1007/s00247-008-0860-7

[9] Scott, P.J., Wharton, G.A. and Gibbs, J.L. (1990) Failure of Doppler Ultrasound to Detect Coarctation of the Aorta. International Journal of Cardiology, 28, 379-381. http://dx.doi.org/10.1016/0167-5273(90)90325-Y 